\title{
Energetic demand and physical conditioning of table tennis players. A study review
}

\section{Alessandro Moura Zagatto, Miran Kondric, Beat Knechtle, Pantelis Theo Nikolaidis \& Billy Sperlich}

To cite this article: Alessandro Moura Zagatto, Miran Kondric, Beat Knechtle, Pantelis Theo Nikolaidis \& Billy Sperlich (2018) Energetic demand and physical conditioning of table tennis players. A study review, Journal of Sports Sciences, 36:7, 724-731, DOI: 10.1080/02640414.2017.1335957

To link to this article: https://doi.org/10.1080/02640414.2017.1335957

$$
\text { 册 Published online: } 05 \text { Jun } 2017 .
$$

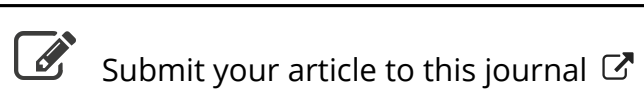

Џ Article views: 585

View Crossmark data ¿ 


\title{
Energetic demand and physical conditioning of table tennis players. A study review
}

\author{
Alessandro Moura Zagatto ${ }^{a}$, Miran Kondric ${ }^{\mathrm{b}, c}$, Beat Knechtle $^{\mathrm{d}}$, Pantelis Theo Nikolaidis ${ }^{\mathrm{e}}$ and Billy Sperlich ${ }^{f}$

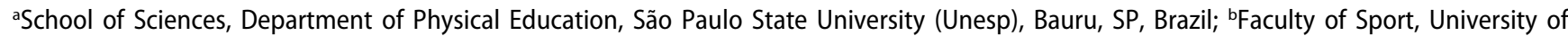 \\ Ljubljana, Ljubljana, Slovenia; International Table Tennis Federation, Lausanne, Switzerland; 'Gesundheitszentrum St. Gallen, St. Gallen, \\ Switzerland; exercise Physiology Laboratory, Nikaia, Greece; fIntegrative and Experimental Training Science, Institute of Sport Science, University \\ of Würzburg, Würzburg, Germany
}

\section{ABSTRACT}

Table tennis is a racket sport characterised by an intermittent movement profile, including short rallies interspersed with short breaks. In contrast to other racket sports, information is lacking regarding the: (i) physiological responses during table tennis matches and training; and (ii) practical recommendations for enhancing aerobic and anaerobic performance in table tennis by improving cardio-metabolic and neuro-muscular fitness, anthropometry and nutritional strategies. Therefore, this review article attempts to narratively provide an overview of the physiology of table tennis by describing the metabolic mechanisms underlying match play and outlining a framework for practical recommendations for improving cardio-metabolic and neuro-muscular fitness, anthropometry as well as nutritional strategies. A second aim was to stimulate future research on table tennis and to point out study limitations in this context. In general, the most important finding is that the rally duration is short at around $3.5 \mathrm{~s}$, with a longer rest time of around 8-20s, resulting in an effort-rest ratio ranging from 0.15 to 0.22 in official matches and energetic demands during match relatively low. Future studies should focus on the relationship between energetic demand and table tennis performance with a view to predicting performance in table tennis using physiological parameters.
ARTICLE HISTORY

Accepted 18 May 2017

\section{KEYWORDS}

Physiological responses; blood lactate;

anthropometric Profile; nutritional aspect; neuro-muscular fitness

\section{Introduction}

Table tennis is a racket sport characterised by an intermittent movement profile, including short rallies of approximately $3 \mathrm{~s}$ interspersed with short breaks (Zagatto, Morel, \& Gobatto, 2010; Zagatto, Papoti, Leite, \& Beneke, 2016). The main tactical goals in table tennis are: (i) to aggravate the opponent's offensive stroke; and (ii) to complete a point as quickly as possible by combining both intense and repetitive efforts. These efforts include rapid leg movements with short accelerations and decelerations as well as the dominant arm performing a powerful stroke (Padulo, Di Giminiani et al., 2016; Padulo, Pizzolato et al., 2016) and fast blocking of the ball after the opponent's counterattack.

From this perspective, success in table tennis requires the capability to perform high-intensity efforts, rapidly recover between rallies and matches and maintain cognitive function (Zagatto \& Gobatto, 2012; Zagatto, Miranda, \& Gobatto, 2011; Zagatto, Papoti, dos Reis, Beck, \& Gobatto, 2014; Zagatto, Papoti et al., 2016). From a physiological point of view, table tennis integrates anaerobic and aerobic pathways for energy production (Sperlich, Koehler, Holmberg, Zinner, \& Mester, 2011; Zagatto et al., 2011, 2010) with phosphocreatine resynthesis during recovery periods. Three major physiological and anthropometric components directly influence aerobic and anaerobic performance in table tennis: (i) elevated cardio-metabolic and neuro-muscular fitness; (ii) favourable anthropometry; and (iii) optimal nutritional strategies.
In contrast to other racket sports like tennis and badminton, scientific knowledge is lacking regarding: (i) the physiological responses during table tennis matches and training; and (ii) practical recommendations for enhancing aerobic and anaerobic performance in table tennis by improving cardiometabolic and neuro-muscular fitness, anthropometry as well as nutritional strategies.

Therefore, this review article attempts to narratively provide an overview of table tennis physiology by describing the metabolic mechanisms underlying match play and outlining a framework for practical recommendations for improving cardio-metabolic and neuro-muscular fitness, anthropometry as well as nutritional strategies. A second aim was to stimulate future research on table tennis and to point out study limitations in this context.

For the present narrative review, we performed a database searching process of relevant literature within the Medline, PubMed, SPORTDiscus, Web of Science and Cochrane databases along with articles published at ITTF Sports Science Congresses, including the International Journal of Table Tennis Sciences. The search terms included "tables tennis", "physiological responses", "testing", "game analysis", "racket sport", "physiological responses", "energetic demand", "aerobic", "anaerobic", "cardiorespiratory", "neuro-muscular", "heart rate", "oxygen uptake", "lactate", "metabolism", "match", and they were also combined. After the initial search for relevant literature, related articles arising from the references acquired from the database searches were 
Table 1. Studies investigating the temporal structure of table tennis including match, rally and rest duration, E:R ratio and number of rally.

\begin{tabular}{|c|c|c|c|c|c|c|c|c|}
\hline Study & Players' Level & Official or Simulated Match & $\begin{array}{c}\text { Match } \\
\text { Duration } \\
\text { (min) }\end{array}$ & $\begin{array}{l}\text { Rally } \\
\text { Duration } \\
\text { (s) }\end{array}$ & $\begin{array}{l}\text { Rest } \\
\text { time } \\
(\mathrm{s})\end{array}$ & E:R Ratio & $\begin{array}{l}\text { Number of shots } \\
\text { per rally }\end{array}$ & $\begin{array}{l}\text { Table Tennis } \\
\text { Rules }\end{array}$ \\
\hline $\begin{array}{l}\text { Zagatto et al. } \\
\qquad(2010)\end{array}$ & $\begin{array}{l}\text { Regional Brazilian } \\
\text { Players (male) }\end{array}$ & Official Tournament) & $14.2 \pm 4.7^{\#}$ & $3.6 \pm 1.9$ & $7.0 \pm 4.5$ & $\begin{array}{l}0.6 \pm 0.2^{*} \\
0.5 \pm 0.2^{* *}\end{array}$ & $3.9 \pm 2.0$ & 2 \\
\hline $\begin{array}{l}\text { Zagatto et al. } \\
(2010)\end{array}$ & $\begin{array}{l}\text { National Brazilian } \\
\text { Players (male) }\end{array}$ & Official Tournament & $19.0 \pm 6.0^{\#}$ & $3.2 \pm 1.3$ & $9.3 \pm 5.5$ & $\begin{array}{l}0.4 \pm 0.1^{*} \\
0.3 \pm 0.1^{* *}\end{array}$ & $3.9 \pm 2.0$ & 2 \\
\hline Leite et al. (2017) & $\begin{array}{l}\text { World Elite Players } \\
\text { (male) }\end{array}$ & $\begin{array}{l}\text { World Championships and } \\
\text { Olympic Games }\end{array}$ & 45.1 & 3.3 & 18.6 & $\begin{array}{l}0.19^{*} \\
0.18^{* *}\end{array}$ & 4.0 & 2 \\
\hline Leite et al. (2017) & $\begin{array}{l}\text { World Elite Players } \\
\text { (male) }\end{array}$ & 2009 World Championship & 45.4 & 3.6 & 17.0 & $\begin{array}{c}0.22^{*} \\
0.21^{* *}\end{array}$ & 5.0 & 2 \\
\hline Leite et al. (2017) & $\begin{array}{l}\text { World Elite Players } \\
\text { (male) }\end{array}$ & 2011 World Championship & 44.1 & 3.3 & 20.2 & $\begin{array}{c}0.16^{*} \\
0.16^{* *}\end{array}$ & 4.0 & 2 \\
\hline Leite et al. (2017) & $\begin{array}{l}\text { World Elite Players } \\
\text { (male) }\end{array}$ & 2012 Olympic Games & 45.1 & 3.1 & 18.9 & $\begin{array}{c}0.17^{*} \\
0.15^{* *}\end{array}$ & 4.0 & 2 \\
\hline $\begin{array}{l}\text { Zagatto, Papoti } \\
\text { et al. (2016) }\end{array}$ & $\begin{array}{l}\text { National Brazilian } \\
\text { Players (male) }\end{array}$ & Simulated match & $24.3 \pm 8,7$ & $3.5 \pm 1.5$ & $8.2 \pm 3.9$ & $0.44 \pm 0.07^{* *}$ & $4.0 \pm 2.2$ & 2 \\
\hline Yuza et al. (1992) & Top Japanese Players & Simulated match & - & $4.6 \pm 2.8$ & - & - & $6.0 \pm 3.6$ & 1 \\
\hline
\end{tabular}

${ }^{*} \mathrm{E}: \mathrm{R}$ ratio within a set and ${ }^{* *} \mathrm{E}: \mathrm{R}$ ratio within a match; \#; table tennis match of 5 sets; 1 : Old rules with speed glue and solvents allowed, sets lasting 21 points and balls of $38 \mathrm{~mm}$; 2: New rules of punctuation, speed glue and solvents banned and cellulose balls of $40 \mathrm{~mm}$; Current rules with plastic ball

scanned. The studies included were limited to the English language and those published before March 2017.

\section{Match analysis and temporal characteristics of table tennis}

The table tennis rules have been amended over the last 15 years. Changes include modifications of the ball size (from $38 \mathrm{~mm}$ to $40 \mathrm{~mm}$ ), match punctuation (sets of 21 points to 11 points with a greater number of sets, five vs. seven), the banning of speed glues, boosters or other chemical solutions applied to the racket so as to alter ball flight properties, i.e. the friction, structure or surface of the racket's rubber in since 2001. Finally, the change in the ball material from cellulose to plastic (i.e. the poly ball) since 2014 generally modified the temporal structure of table tennis.

In an initial attempt to analyse the temporal characteristics of table tennis, Künstlinger, Preuss, and Schiefler (1998) reported that rallies on average lasted for $3.3 \mathrm{~s}$, with a recovery period of approximately $8 \mathrm{~s}$. Temporal analysis of the 2000 World Championship revealed a slower ball speed when playing with the new $40 \mathrm{~mm}$ diameter ball compared to the $38 \mathrm{~mm}$ ball and that simultaneously the rally time increased from 3.1 to $3.8 \mathrm{~s}$ (no standard deviation available) with the new $40 \mathrm{~mm}$ compared to the $38 \mathrm{~mm}$ ball (Takeuchi, Kobayashi, Hiruta, \& Yuza, 2001). Similar analyses showed that the average rally time was $2 \%-4 \%$ longer for drive and chop shots with the $40 \mathrm{~mm}$ ball compared to the $38 \mathrm{~mm}$ one (Tang, Mizoguchi, \& Toyoshima, 2002).

Zagatto, Papoti et al. (2016), Zagatto et al. (2010) reported the rally time in simulated matches of regional and national Brazilian table tennis players lasted about $3.2 \pm 1.3$ to $3.6 \pm 1.9$ s. Similarly, others (Leite, Barbieri, Miyagi, Malta, \& Zagatto, 2017) analysed the 2009 and 2011 World Championships and the 2012 Olympic Games with the median $\left(1^{\text {st }}\right.$ quartile- $3^{\text {rd }}$ quartile) rally times of $3.6(2.9-4.9) \mathrm{s}$ and 3.3 (2.7-4.3) s during the World Championships and $3.1(2.5-4.0) \mathrm{s}$ during the Olympic Games. It is worth noting that the rally times decreased significantly at the finals [3.1 (2.5-4.1) s] compared to the semi-finals [3.2 (2.6-4.2) s] and quarterfinals
[3.5 (2.8-4.6) s], but without any change in the number of shots per rally [4.0 (3.0--6.0) shots per rally] (Leite et al., 2017). In summary, despite the frequent changes made to the table tennis regulations in the last few years the duration of a rally averages out at $3.5 \mathrm{~s}$ on the elite and sub-elite level.

However, the association of rally time and rest time can result in relevant changes, mainly in the ratio between effort and rest time. In general, the effort-rest ratio ( $E: R$ ratio, i.e. rally time to rest time) observed during table tennis is approximately 0.5 (Zagatto, Papoti et al., 2016; Zagatto et al., 2010) in simulated matches. However, the magnitude of this ratio is lower when measured in official matches, with values ranging from 0.15 to 0.22 (Leite et al., 2017) attributable to a longer rest time (8 to $20 \mathrm{~s}$ of rest) (Leite et al., 2017). In addition, the rest time increases from 17.3 to $20.1 \mathrm{~s}$ within an ongoing tournament (i.e. quarterfinal matches vs. semi-finals vs. finals matches) (Leite et al., 2017).

Table 1 summarises those studies investigating the temporal structure of table tennis including match, rally and rest duration, the $E: R$ ratio and number of rallies.

In summary, rally time among elite and sub-elite table tennis players lasts approximately $3.5 \mathrm{~s}$, with a rest time of about 8 to $20 \mathrm{~s}$ depending on the tournament structure and amount of games, resulting in an E:R ratio of 0.12 to 0.5.

\section{Energetic and metabolic demands in a table tennis match}

Compared to other racket sports like tennis (Ferrauti, Bergeron, Pluim, \& Weber, 2001; Seliger, Ejem, Pauer, \& Safarik, 1973) or badminton (Faccini \& Dai Monte, 1996; Faude et al., 2007), a paucity data is available regarding the cardio-metabolic and hormonal demands during match play in table tennis (Baron et al., 1992; Ma, Liu, \& Liu, 2014; Martin et al., 2015; Zagatto \& Gobatto, 2012; Zagatto et al., 2011, 2010; Zagatto, Papoti et al., 2016).

Since a table tennis competition induces a high level of emotional stress to a player, as evidenced by the ratio between norepinephrine and epinephrine hormones release (Baron et al., 1992), and the playing style influences the match 
characteristics and thus a player's physiological responses (Martin et al., 2015), energetic and metabolic demands should be assessed during real scenario competition conditions.

Gas exchange measurements using portable devices are employed in sports science to estimate energetic and metabolic demands even when workloads change rapidly (Faude et al., 2007; Sperlich et al., 2011). As an initial estimate, Sperlich and co-workers (2011) analysed the oxygen uptake $\mathrm{VO}_{2}$ kinetics of elite youth German table tennis players during

exercise and competition. They found $\mathrm{VO}_{2}$ mean values of approximately $20-25 \mathrm{~mL} / \mathrm{kg} / \mathrm{min}$, with high fluctuations peaking to values of $45 \mathrm{~mL} / \mathrm{kg} / \mathrm{min}$.

The $\mathrm{VO}_{2}$ reported in elite youth table tennis players is lower than that reported for internationally ranked badminton players (43.8-63.4 mL/kg/min) (Faude et al., 2007) and similar to nationally ranked senior tennis players $(25.6 \mathrm{~mL} / \mathrm{kg} / \mathrm{min})$ (Ferrauti et al., 2001).

It is highly desirable to assess $\mathrm{VO}_{2}$ during a competition due to its strong alignment with substrate utilisation, while portable gas analysers, given the additional mass of the device itself with a constricting facial mask and limited visibility, create additional stress for a player and may lead to biased values.

For this reason, indirect measurements of energetic and metabolic demands using heart rate analyses have previously been performed to estimate energetic demands during competition and training in table tennis, averaging out at $60 \%-$ $65 \%$ of peak heart rate in elite youth table tennis players (Sperlich et al., 2011) and $81.2 \pm 7.4 \%$ of the predicted maximum heart rate in regionally to internationally experienced table tennis players during competition (Zagatto et al., 2010).

However, since heart rate is also affected by numerous factors including psychological stress (Baron et al., 1992) as well as fluid loss (Noakes, 1993), estimating energetic and metabolic demands using a heart rate measurement may therefore be inaccurate. To resolve this issue, wearable sensors have been applied to quantify the energetic demands during training and competition, showing a high correlation with indirect calorimetry with an average energy expenditure of $4.8 \pm 1.4$ METs during elite youth table tennis competition and $7.8 \pm 2.0$ METs during high-intensity training drills (Sperlich et al., 2011).

Finally, dense measurements of blood lactate values before, during and after a match have been taken to estimate the metabolic and energetic demands of table tennis play. With this approach, blood lactate values of $1.1 \pm 0.2 \mathrm{mmol} / \mathrm{L}$ during competition and $1.5 \pm 1.0 \mathrm{mmol} / \mathrm{L}$ during high-intensity training drills have been reported in elite youth table tennis players (Sperlich et al., 2011). Similar values, i.e. $1.8 \pm 0.8 \mathrm{mmol} / \mathrm{L}$ (peak lactate values: $2.2 \pm 0.8 \mathrm{mmol} / \mathrm{L}$ ) during official tournaments of regionally to internationally experienced table tennis players have been reported previously (Zagatto et al., 2010).

Since blood lactate levels during table tennis competitions are generally low $(<2 \mathrm{mmol} / \mathrm{L})$ and based on the aforementioned data involving available gas exchange data, heart rate and multi-sensor measurements, we may conclude that the energetic and metabolic demands of a table tennis match heavily involve aerobic, with little contribution of anaerobic- lactic, energy pathways. Since during elite and sub-elite table tennis the rally times are approximately $3.5 \mathrm{~s}$, with fairly long rest times of 8 to $20 \mathrm{~s}$, we may also conclude that the anaerobic a-lactic pathway is dominant in table tennis.

Some evidence shows that aerobic metabolism is responsible for the fast reestablishment of phosphocreatine stores during recovery (Bishop, Edge, Davis, \& Goodman, 2004; Tomlin \& Wenger, 2001) and would allow a player to perform the next rally more recovered. However, Zagatto, Papoti et al. (2016) found no significant correlation between peak oxygen uptake with estimated anaerobic a-lactic $(r=-0.31 ; P=0.28)$ and glycolytic $(r=0.53 ; P=0.10)$ energetic contribution during a match.

To summarise, in table tennis the aerobic [approximately 96\% (Zagatto, Papoti et al., 2016)] and anaerobic a-lactic pathways [4\% (Zagatto, Papoti et al., 2016)] dominate in energy production.

\section{Physical characteristics of table tennis players \\ Cardio-respiratory data}

The peak oxygen uptake of nationally ranked Brazilian players determined on a treadmill $(43.9 \pm 1.5 \mathrm{~mL} / \mathrm{kg} / \mathrm{min})$ and a cycling ergometer were similar $(41.3 \pm 1.4 \mathrm{~mL} / \mathrm{kg} / \mathrm{min})$ but higher than when measured during a specific test $(36.9 \pm 1.5 \mathrm{~mL} / \mathrm{kg} / \mathrm{min})$ and arm cranking $(26.6 \pm 1.6 \mathrm{~mL} / \mathrm{kg} /$ min), while the $\mathrm{VO}_{2}$ at $\mathrm{VT}_{2}$ was $37.7 \pm 1.7,33.8 \pm 1.5$, $35.2 \pm 2.2$ and $18.0 \pm 1.1 \mathrm{~mL} / \mathrm{kg} / \mathrm{min}$, respectively (Zagatto et al., 2014). Using a specific table tennis test, the same group of authors (Zagatto et al., 2011) reported a maximal oxygen uptake $\mathrm{VO}_{2 \max }$ of $49.8 \pm 1.1 \mathrm{~mL} / \mathrm{kg} / \mathrm{min}$, while the $\mathrm{VT}_{2}$ corresponded to $47.4 \pm 3.4 \mathrm{balls} / \mathrm{min}$, representing $81.9 \pm 3.4 \%$ of the peak intensity obtained during the test.

$\mathrm{VO}_{2 \max }$ measured in a table-tennis-specific test corresponded to $44.0 \pm 4.5 \mathrm{~mL} / \mathrm{kg} / \mathrm{min}$ (Zagatto, Papoti et al., 2016). The test was performed using a robot to launch balls, with the ball-launch frequency increasing after every 2 minutes of effort. The maximal frequency (i.e. maximal intensity) obtained in this test was $59.1 \pm 6.9 \mathrm{balls} / \mathrm{min}$, with aerobic endurance determined by the $\mathrm{VT}_{2}$ method corresponding to an intensity of $44.0 \pm 3.7 \mathrm{balls} / \mathrm{min}$ and an oxygen uptake of $35.2 \pm 4.7 \mathrm{~mL} / \mathrm{kg} / \mathrm{min}$.

These findings revealed that table tennis players possess quite a low aerobic capacity $\mathrm{VO}_{2 \max }=$ approximately $\mathrm{mL} / \mathrm{kg} /$ min) (Zagatto et al., 2011, 2014; Zagatto, Papoti et al., 2016), which is lower than observed in other racket sports players such tennis [approximately $58 \mathrm{~mL} \cdot \mathrm{kg}^{-1} \cdot \mathrm{min}^{-1}$ (Girard, Chevalier, Leveque, Micallef, \& Millet, 2006; Smekal et al., 2001)], squash [approximately $64 \mathrm{~mL} \cdot \mathrm{kg}^{-1} \cdot \mathrm{min}^{-1}$ (Girard et al., 2005)] and badminton players (approximately $60 \mathrm{~mL} \cdot \mathrm{kg}^{-1} \cdot \mathrm{min}^{-1}$ (Carlson, Tyrrell, Naughton, Laussen, \& Portier, 1985).

Zagatto et al. (2014) also evaluated the respiratory compensation point in treadmill running and found that the compensation point occurred at $11.4 \pm 0.4 \mathrm{~km} / \mathrm{h}$, namely lower than the $4.0 \mathrm{mmol} / \mathrm{L}$ blood lactate observed in tennis players $(12.6 \pm 1.9 \mathrm{~km} / \mathrm{h})$ (Smekal et al., 2001). Despite of table tennis 
has a higher aerobic contribution during match, the table tennis players have a lower aerobic capacity compared to other racket sports and thus they must to give more attention to this physical component, mainly for elite players and defensive players who play longer points and try to be more regular.

\section{Anaerobic indices}

The anaerobic metabolisms are the main energy pathways active during the table tennis efforts, and therefore, the a-lactic and lactic metabolism have a relevant role for table tennis performance. Traditionally, the anaerobic power of the leg muscles is estimated by a short 30-s cycle test such as the Wingate test. Elite male $(n=4)$ Slovenian national team players showed a peak power of $9.60 \pm 0.79 \mathrm{~W} / \mathrm{kg}$ and a mean power of $7.95 \pm 0.88 \mathrm{~W} / \mathrm{kg}$, while elite Slovenian female players $(n=4)$ had a peak power of $8.03 \pm 0.78 \mathrm{~W} / \mathrm{kg}$ and a mean power of $6.55 \pm 0.54 \mathrm{~W} / \mathrm{kg}$ (Kondrič, Milić, \& FurjanMandić, 2007). These values are lower than those for national Brazilian players (peak power: $11.6 \pm 0.76 \mathrm{~W} / \mathrm{kg}$; mean power $9.06 \pm 0.76 \mathrm{~W} / \mathrm{kg}$ ) (Zagatto et al., 2004), but higher than for youth elite tennis players (peak power: $8.6 \mathrm{~W} / \mathrm{kg}$; mean power: $7.4 \mathrm{~W} / \mathrm{kg}$ ) (Bencke et al., 2002). Zagatto et al. (2004) also applied the Wingate test on an arm crank ergometer to evaluate upper body power, and the results for peak and mean power were $5.7 \pm 0.7 \mathrm{~W} / \mathrm{kg}$ and $4.1 \pm 0.5 \mathrm{~W} / \mathrm{kg}$.

Zagatto and Gobatto (2012) adapted the maximal accumulated oxygen deficit test (MAOD), which is the generally accepted test for estimating anaerobic capacity for table tennis, by using a robot to launch balls while the players performed forehand offensive strokes. The MAOD corresponded to $4.23 \pm 1.53 \mathrm{~L}(71.6 \pm 29.8 \mathrm{~mL} / \mathrm{kg})$. In general, the MAOD values found in table tennis players are similar to those observed in moderately active men (de Poli, Miyagi, Nakamura, \& Zagatto, 2016; Zagatto, Bertuzzi, Miyagi, Padulo, \& Papoti, 2016), but lower than for athletes from sports with a high anaerobic demand such as rugby players (Moore \& Murphy, 2003) and sprinters (Gastin \& Lawson, 1994).

Zagatto, Papoti et al. (2016) showed that the MAOD (i.e. anaerobic capacity) determined in a specific table tennis procedure was moderate and significantly correlated with the rate of shots in a simulated match $(r=0.58 ; P<0.05)$, showing that greater anaerobic capacity enables rallies to be played at a higher intensity.

\section{Strength indices}

Preliminary analyses showed that male table tennis players compared to female ones have better handgrip isometric strength (Picabea, Cámara, \& Yanci, 2017).

The forehand and backhand attack actions (i.e. topspin and counterattacking strokes) during table tennis involve $53 \%$ of all stroke types (Lanzoni, Di Michele, \& Merni, 2014). Therefore, arm speed and acceleration, are the most important components in performing a powerful stroke. Bańkosz and Winiarski (2017) reported that the maximum racket speed occurring at the moment of ball impact is probably the one of the key biomechanical requirement for a successful playing technique which relies on the mastered ability to accelerate the arm during the repetitive tennis table strokes. Several decisive actions (i.e. offensive strokes) during a table tennis game involve the power of the arm to yield velocity and arm acceleration and consequently that of the ball.

\section{Strategies to improve aerobic and anaerobic components in table tennis}

Based on the above analysis, a table tennis player possesses a reasonably low $\mathrm{VO}_{2}$ (approximately 40 to $50 \mathrm{~mL} / \mathrm{kg} / \mathrm{min}$ ) (Zinner, Sperlich, Wahl, \& Mester, 2015) and the $\mathrm{V} \mathrm{O}_{2}$ demands during match play are quite small (approximately $20-25 \mathrm{~mL}$ / $\mathrm{kg} / \mathrm{min}$ ), leading to the conclusion that the energy contribution in table tennis depends predominantly on aerobic [approximately 96\% (Zagatto, Papoti et al., 2016)] and anaerobic a-lactic pathways [4\% (Zagatto, Zagatto, Papoti et al., 2016)].

In the past, several strategies were proposed to improve variables related to the aerobic and anaerobic components of various sports, including training methods with different intensity domains (Stoggl \& Sperlich, 2014). From a practical point of view, three major domains assist in prescribing the intensity of exercise:

(i) low-intensity exercise corresponding to $<2 \mathrm{mmol} / \mathrm{L}$ blood lactate or $<1^{\text {st }}$ ventilatory threshold $\left(\mathrm{VT}_{1}\right)$ or based upon the perception of <"somewhat hard" equivalent to $<13$ on Borg's scale (Borg, 1970);

(ii) "threshold intensity" exercise at 2-4 $\mathrm{mmol} / \mathrm{L}$ blood lactate, $>\mathrm{VT}_{1}$ and $<\mathrm{VT}_{2}$, the perception of "hard" equivalent to 14-16 on Borg's scale); and

(iii) high-intensity exercise (i.e. $>4 \mathrm{mmol} / \mathrm{L}$ blood lactate, $>\mathrm{VT}_{2}$, the perception of $>$ "very hard" equivalent to $>17$ on Borg's scale).

From a time perspective, exercise involving high-intensity exercise seems intriguing since similar (Burgomaster et al., 2008) or even superior aerobic and anaerobic adaptations (Maclnnis et al., 2016) have been found compared to continuous low-intensity exercise. High-intensity exercise is often prescribed as an intensity corresponding to $75 \%-170 \%$ of

$\mathrm{VO}_{2 \max }$ (Helgerud et al., 2007; Laursen \& Jenkins, 2002; Wenger \& Bell, 1986) or $90 \%-100 \%$ of peak heart rate (Helgerud et al., 2007) or $80 \%-175 \%$ of peak power (Laursen \& Jenkins, 2002).

From a practical perspective, the duration of an interval may last from seconds to minutes, including 4-47 repetitions (Gibala et al., 2006; Helgerud et al., 2007; Laursen \& Jenkins, 2002) with passive or active recovery between the bouts (Billat, 2001; Billat et al., 2000) and also in a sport-specific manner (Chamari et al., 2005; Hill-Haas, Coutts, Rowsell, \& Dawson, 2009; Impellizzeri et al., 2006; Kindermann, Coen, \& Urhausen, 1998; McMillan, Helgerud, Macdonald, \& Hoff, 2005; Owen, Wong del, Paul, \& Dellal, 2012).

Therefore, from a coach's perspective, a high-intensity exercise allows an infinite amount of possibilities to improve sportspecific aerobic and anaerobic components. However, to the best of our knowledge no study has investigated the 
responses of different training methods to improve aerobic and anaerobic components in table tennis players.

Recently, in endurance athletes the combination of lowintensity exercise and high-intensity exercise at a training time ratio of approximately 4:1 ratio stimulated greater improvements in most key variables of endurance performance (including $\mathrm{VO}_{2 \max }$ ) compared to high-volume, threshold or high-intensity exercise (Stoggl \& Sperlich, 2014). Whether the combined strategy of high-volume, low-intensity and lowvolume, high-intensity exercise is also beneficial for improving the aerobic and anaerobic components in table tennis players is a question for further research. However, since low and moderate actions represented an important proportion $(84.3 \pm 4.7 \%)$ of the actions performed by table tennis players, whereas high-intensity actions represented $15.7 \pm 4.7 \%$ (Le Mansec, Seve, \& Jubeau, 2017) a combined training strategy (i.e. high-volume, low-intensity and low-volume, high-intensity training) may be reasonable for improving the aerobic and anaerobic components in table tennis.

\section{Anthropometric characteristics and body composition of table tennis players}

Monitoring anthropometric characteristics and body composition in table tennis might help coaches to identify talented players and optimise training programmes. The anthropometric characteristics widely collected in previous table tennis studies were body mass, height and body mass index (BMI) (Munivrana, Paušić, \& Kondrič, 2011a, 2011b; Pradas de la Fuente, González Jurado, Molina Sotomayor, \& Castellar Otín, 2013; Zagatto, Milioni, Freitas, Arcangelo, \& Padulo, 2016). In addition to the abovementioned characteristics, human physique might be classified using somatotype with a popular assessment method being that of Health-Carter (Sepúlveda, Barraza, Soto, Báez, \& Tuesta, 2015). Briefly, this method consists of a three-level scale reflecting endomorphy, i.e. relative fatness, mesomorphy, i.e. relative musculoskeletal robustness, and ectomorphy, i.e. relative linearity or slenderness (Heath \& Carter, 1967).

The knowledge regarding table tennis players' anthropometric profile is based on rare research that compared players of different levels and resulted in conflicting results (Sepúlveda et al., 2015; Zagatto, Milioni et al., 2016). For instance, a study on Brazilian table tennis players showed that international players were shorter than national and regional players in men, but not in women (Zagatto, Milioni et al., 2016). Male Spanish table tennis players are balanced mesomorphs, whereas female were mesomorphic endomorphs (Pradas de la Fuente et al., 2013). Male Chilean table tennis players were endomorphic mesomorphs (Sepúlveda et al., 2015).

Body composition has been a major component of healthand sport-related physical fitness and a five-level model has been routinely used to study this component (Wang, Pierson, \& Heymsfield, 1992). The fourth level (tissues-systems) of this model was applied in previous table tennis studies (Sepúlveda et al., 2015; Zagatto, Milioni et al., 2016), where two components of the human body were considered, fat mass and fatfree mass which can be estimated by proxy measures such as skinfold thickness (Garrido-Chamorro, Sirvent-Belando,
González-Lorenzo, Blasco-Lafarga, \& Roche, 2012; Sepúlveda et al., 2015) or assessed directly (e.g. Dual energy X-ray absorptiometry) (Zagatto, Milioni et al., 2016). No difference in muscle tissue, adipose tissue and skinfold thickness was observed among Chilean national team and university table tennis players (Sepúlveda et al., 2015). In agreement with this finding, no difference in either fat mass or fat-free mass was shown among international-, national- and regional-level table tennis Brazilian players (Zagatto, Milioni et al., 2016). Moreover, a study comparing skinfold thickness among different sports indicated that table tennis was among those sports with greater fat mass (Garrido-Chamorro et al., 2012).

In summary: (i) table tennis players possess short-to-average body height and "normal" (compared to body height) body mass; (ii) fat mass does not discriminate table tennis players by performance level; and (iii) the existing knowledge on anthropometric characteristics and body composition relied on a limited number of references. Therefore, the above observations should be treated with caution and further research in this area is warranted, especially on the anthropometric characteristics of table tennis players from countries dominating this sport such as China.

\section{Nutritional aspects of table tennis performance}

Nutrition plays a key role in racket sports as it might influence both training and match performance, e.g. by providing adequate replenishment of energy stores between training sessions (MacLaren, 1998). Little is known about nutrition in table tennis, but some evidence may be extrapolated from research in tennis (Brink-Elfegoun et al., 2014; Gomes, Moreira, Coutts, Capitani, \& Aoki, 2014; Ranchordas, Rogersion, Ruddock, Killer, \& Winter, 2013). To determine the nutritional demands of table tennis, a major aspect might be the caloric demands of a match, which can routinely be evaluated using indirect calorimetry (McNaughton \& Cahn, 1970; Zagatto, Papoti et al., 2016). One of the early studies on table tennis and nutrition (McNaughton \& Cahn, 1970) reported a caloric cost of playing table tennis $(4.6 \mathrm{kcal} / \mathrm{min})$ higher than laboratory work (1.4-2.3 kcal/min), but lower than cycling $(3.6-6.0 \mathrm{kcal} /$ $\mathrm{min}$ ) and running (5.2-7.5 $\mathrm{kcal} / \mathrm{min})$. Compared to other racket sports, table tennis has similar caloric demands (29-42 kJ/min) as badminton (29-46 kJ/min) and tennis (29-46 kJ/min) (Ranchordas et al., 2013), but lower than squash (42-76 kJ/ min) (MacLaren, 1998).

Racket sports athletes are recommended to consume a minimum of $55 \%$ of the total energy intake in the form of carbohydrates (MacLaren, 1998) equal to 6-10 g per kg body mass per day (Ranchordas et al., 2013). Carbohydrate ingestion before playing table tennis might have a positive effect on performance since, at least in badminton, carbohydrate ingestion improved serving accuracy (Bottoms, Sinclair, Taylor, Polman, \& Fewtrell, 2012). Although match play in table tennis is shorter than in tennis, carbohydrate ingestion helps to maintain glycaemia (Gomes et al., 2014).

Since table tennis training and matches are practised indoors where temperature and humidity are more controlled than outdoors, table tennis players might also be affected by the combined effect of dehydration and elevated temperature. The 
important role of hydration, especially in the presence of hot temperature, was highlighted in a study (Therminarias, Dansou, Chirpaz, Eterradossi, \& Favre-Juvin, 1995) where a limited fluid intake combined with playing tennis in a hot environment resulted in increased heart rate, rectal temperature, fluid loss, cramps and heat stroke. At least for tennis players, adequate hydration and the ingestion of balanced meals between matches assists in maintaining physical performance even during consecutive competitive matches (Brink-Elfegoun et al., 2014). With regard to nutritional habits, it was observed that the majority of competitive table tennis players were not informed by their coaches and physicians about nutritional supplements and, moreover, their risk for doping increased by performance level (Kondric, Sekulic, \& Mandic, 2010).

\section{Final considerations}

In this review, we presented information about temporal analyses and energetic demands during a table tennis match, the physical characteristics of elite table tennis players, strategies to improve aerobic and anaerobic components in table tennis, and nutritional aspects of table tennis performance. In general, we showed that the duration of a rally is short at around $3.5 \mathrm{~s}$, with a longer rest time of around 8-20 s, resulting in an effortrest ratio ranging from 0.15 to 0.22 in official elite matches. However, the energetic demands during a table tennis match are relatively low. Despite some relevant studies about physiological responses in table tennis and measuring physical conditioning in table tennis players, additional aspects such as strength, flexibility, arm power, speed and change of direction and others still need be investigated, as well as future studies should investigate the role of the "accuracy" of the strokes (i.e., forehand, backhand, service and others) to predict the performance during table tennis. In addition, the role of all of these parameters in table tennis performance must be examined. Future studies need to focus on the relationship between energetic demand and table tennis performance with a view to predicting performance in table tennis using physiological parameter

\section{Disclosure statement}

No potential conflict of interest was reported by the authors.

\section{References}

Bańkosz, Z., \& Winiarski, S. (2017). The kinematics of table tennis racquet: Differences between topspin strokes. The Journal of Sports Medicine and Physical Fitness, 57(3), 202-213.

Baron, R., Petschnig, R., Bachl, N., Raberger, G., Smekal, G., \& Kastner, P. (1992). Catecholamine excretion and heart rate as factors of psychophysical stress in table tennis. International Journal of Sports Medicine, 13(7), 501-505.

Bencke, J., Damsgaard, R., Saekmose, A., Jorgensen, P., Jorgensen, K., \& Klausen, K. (2002). Anaerobic power and muscle strength characteristics of 11 years old elite and non-elite boys and girls from gymnastics, team handball, tennis and swimming. Scandinavian Journal of Medicine \& Science in Sports, 12(3), 171-178.

Billat, L. V. (2001). Interval training for performance: A scientific and empirical practice. Special recommendations for middle- and long- distance running. Part I: Aerobic interval training. Sports Medicine, 31 (1), 13-31.

Billat, V. L., Slawinski, J., Bocquet, V., Demarle, A., Lafitte, L., Chassaing, P., \& Koralsztein, J. P. (2000). Intermittent runs at the velocity associated with maximal oxygen uptake enables subjects to remain at maximal oxygen uptake for a longer time than intense but submaximal runs. European Journal of Applied Physiology and Occupational Physiology, 81(3), 188196. doi: $10.1007 / \mathrm{s} 004210050029$

Bishop, D., Edge, J., Davis, C., \& Goodman, C. (2004). Induced metabolic alkalosis affects muscle metabolism and repeated-sprint ability. Medicine and Science in Sports and Exercise, 36(5), 807-813.

Borg, G. (1970). Perceived exertion as an indicator of somatic stress. Scandinavian Journal of Rehabilitation Medicine, 2(2), 92-98.

Bottoms, L., Sinclair, J., Taylor, K., Polman, R., \& Fewtrell, D. (2012). The effects of carbohydrate ingestion on the badminton serve after fatiguing exercise. Journal of Sports Sciences, 30(3), 285-293. doi:10.1080/ 02640414.2011 .637948

Brink-Elfegoun, T., Ratel, S., Lepretre, P. M., Metz, L., Ennequin, G., Dore, E., ... Peltier, S. L. (2014). Effects of sports drinks on the maintenance of physical performance during 3 tennis matches: A randomized controlled study. Journal of the International Society of Sports Nutrition, 11, 46. doi:10.1186/s12970-014-0046-7

Burgomaster, K. A., Howarth, K. R., Phillips, S. M., Rakobowchuk, M., Macdonald, M. J., McGee, S. L., \& Gibala, M. J. (2008). Similar metabolic adaptations during exercise after low volume sprint interval and traditional endurance training in humans. The Journal of Physiology, 586(1), 151-160. doi:10.1113/jphysiol.2007.142109

Carlson, J., Tyrrell, J., Naughton, G., Laussen, S., \& Portier, B. (1985). Physiological responses during badminton games by elite Australian players. Badminton Sitelines, 13, 17-20.

Chamari, K., Hachana, Y., Kaouech, F., Jeddi, R., Moussa-Chamari, I., \& Wisloff, U. (2005). Endurance training and testing with the ball in young elite soccer players. British Journal of Sports Medicine, 39(1), 24-28. doi:10.1136/bjsm.2003.009985

de Poli, R., Miyagi, W. E., Nakamura, F. Y., \& Zagatto, A. M. (2016). Caffeine improved time to exhaustion, but did not change alternative maximal accumulated oxygen deficit estimated during a single supramaximal running bout. International Journal of Sport Nutrition and Exercise Metabolism, 26(6), 549-557. doi:10.1123/ijsnem.2016-0038

Faccini, P., \& Dai Monte, A. (1996). Physiologic demands of badminton match play. The American Journal of Sports Medicine, 24(6 Suppl), S64-66.

Faude, O., Meyer, T., Rosenberger, F., Fries, M., Huber, G., \& Kindermann, W. (2007). Physiological characteristics of badminton match play. European Journal of Applied Physiology and Occupational Physiology, 100(4), 479485. doi:10.1007/s00421-007-0441-8

Ferrauti, A., Bergeron, M. F., Pluim, B. M., \& Weber, K. (2001). Physiological responses in tennis and running with similar oxygen uptake. European Journal of Applied Physiology and Occupational Physiology, 85(1-2), 2733. doi: $10.1007 / \mathrm{s} 004210100425$

Garrido-Chamorro, R., Sirvent-Belando, J. E., González-Lorenzo, M., BlascoLafarga, C., \& Roche, E. (2012). Skinfold sum: Reference values for top athletes. International Journal of Morphology, 30(3), 803-809. doi:10.4067/S0717-95022012000300005

Gastin, P. B., \& Lawson, D. L. (1994). Influence of training status on maximal accumulated oxygen deficit during all-out cycle exercise. European Journal of Applied Physiology and Occupational Physiology, 69(4), 321330.

Gibala, M. J., Little, J. P., van Essen, M., Wilkin, G. P., Burgomaster, K. A., Safdar, A., ... Tarnopolsky, M. A. (2006). Short-term sprint interval versus traditional endurance training: Similar initial adaptations in human skeletal muscle and exercise performance. The Journal of Physiology, 575(Pt(3)), 901-911. doi:10.1113/jphysiol.2006.112094

Girard, O., Chevalier, R., Leveque, F., Micallef, J. P., \& Millet, G. P. (2006). Specific incremental field test for aerobic fitness in tennis. British Journal of Sports Medicine, 40(9), 791-796. doi:10.1136/ bjsm.2006.027680

Girard, O., Sciberras, P., Habrard, M., Hot, P., Chevalier, R., \& Millet, G. P. (2005). Specific incremental test in elite squash players. British Journal of Sports Medicine, 39(12), 921-926. doi:10.1136/bjsm.2005.018101 
Gomes, R. V., Moreira, A., Coutts, A. J., Capitani, C. D., \& Aoki, M. S. (2014). Effect of carbohydrate supplementation on the physiological and perceptual responses to prolonged tennis match play. Journal of Strength and Conditioning Research, 28(3), 735-741. doi:10.1519/JSC.0b013e3182a1f757

Heath, B. H., \& Carter, J. E. (1967). A modified somatotype method. American Journal of Physical Anthropology, 27(1), 57-74.

Helgerud, J., Hoydal, K., Wang, E., Karlsen, T., Berg, P., Bjerkaas, M., ... Hoff, J. (2007). Aerobic high-intensity intervals improve VO2max more than moderate training. Medicine and Science in Sports and Exercise, 39(4), 665-671. doi:10.1249/mss.0b013e3180304570

Hill-Haas, S. V., Coutts, A. J., Rowsell, G. J., \& Dawson, B. T. (2009). Generic versus small-sided game training in soccer. International Journal of Sports Medicine, 30(9), 636-642. doi:10.1055/s-0029-1220730

Impellizzeri, F. M., Marcora, S. M., Castagna, C., Reilly, T., Sassi, A., Iaia, F. M., \& Rampinini, E. (2006). Physiological and performance effects of generic versus specific aerobic training in soccer players. International Journal of Sports Medicine, 27(6), 483-492. doi:10.1055/s-2005-865839

Kindermann, W., Coen, B., \& Urhausen, A. (1998). Leistungsphysiologische Massnahmen im Fußball und Handball. Deutsche Zeitschrift Fuer Sportmedizin (Performance-physiological examinations in soccer and handbal), 49(Sonderheft 1), 56-60.

Kondrič, M., Milić, R., \& Furjan-Mandić, G. (2007). Physiological anaerobic characteristics of Slovenian elite table tennis players. Acta Universitatis Palackianae Olomucensis. Gymnica, 37(3), 69-78.

Kondric, M., Sekulic, D., \& Mandic, G. F. (2010). Substance use and misuse among slovenian table tennis players. Substance Use \& Misuse, 45(4), 543-553. doi:10.3109/10826080903452553

Künstlinger, U., Preuss, A., \& Schiefler, B. (1998). The energy metabolism in competitive table tennis. International Journal of Sports Medicine, 9 , 395-395.

Lanzoni, I. M., Di Michele, R., \& Merni, F. (2014). A notational analysis of shot characteristics in toplevel table tennis players. European Journal of Sport Science, 14(4), 309-317. doi:10.1080/17461391.2013.819382

Laursen, P. B., \& Jenkins, D. G. (2002). The scientific basis for high-intensity interval training: Optimising training programmes and maximising performance in highly trained endurance athletes. Sports Medicine, 32(1), 53-73.

Le Mansec, Y., Seve, C., \& Jubeau, M. (2017). Neuromuscular fatigue and time motion analysis during a table tennis competition. Journal of Sports Medicine and Physical Fitness, 57(4), 353-361. doi:10.23736/ S0022-4707.16.06129-6

Leite, J. V. M., Barbieri, F. A., Miyagi, W., Malta, E. S., \& Zagatto, A. M. (2017). Influence of game evolution and the phase of competition on temporal game structure in high-level table tennis tournaments. Journal of Human Kinetics, 55, 55-67.

Ma, G., Liu, Y., \& Liu, K. (2014). Influence of repeated bouts of table tennis training on cardiac biomarkers in children. Pediatric Cardiology, 35(4), 711-718. doi:10.1007/s00246-013-0842-x

MacInnis, M. J., Zacharewicz, E., Martin, B. J., Haikalis, M. E., Skelly, L. E., Tarnopolsky, M. A., ... Gibala, M. J. (2016). Superior mitochondrial adaptations in human skeletal muscle after interval compared to continuous single-leg cycling matched for total work. The Journal of Physiology. doi:10.1113/JP272570

MacLaren, D. P. M. (1998). Nutrition for racket sports. In A. Lees, I. Maynard, M. Hughes, \& T. Reilly (Eds.), Science and racket sports. London: E \& FN Spon.

Martin, C., Favier-Ambrosini, B., Mousset, K., Brault, S., Zouhal, H., \& Prioux, J. (2015). Influence of playing style on the physiological responses of offensive players in table tennis. The Journal of Sports Medicine and Physical Fitness, 55(12), 1517-1523.

McMillan, K., Helgerud, J., Macdonald, R., \& Hoff, J. (2005). Physiological adaptations to soccer specific endurance training in professional youth soccer players. British Journal of Sports Medicine, 39(5), 273-277. doi:10.1136/bjsm.2004.012526

McNaughton, J. W., \& Cahn, A. J. (1970). A study of the energy expenditure and food intake of five boys and four girls. British Journal of Nutrition, 24(1), 345-355. doi:10.1079/BJN19700033

Moore, A., \& Murphy, A. (2003). Development of an anaerobic capacity test for field sport athletes. Journal of Science and Medicine in Sport, 6(3), 275-284.
Munivrana, G., Paušić, J., \& Kondrič, M. (2011a). The incidence of improper postural alignment due to the influence of long-term table tennis training. Kinesiologia Slovenica, 17(2), 47-58.

Munivrana, G., Paušić, J., \& Kondrič, M. (2011b). The influence of somatotype on young table tennis players' competitive success. Kinesiologia Slovenica, 17(1), 42-51.

Noakes, T. D. (1993). Fluid replacement during exercise. Exercise and Sport Sciences Reviews, 21, 297-330.

Owen, A. L., Wong del, P., Paul, D., \& Dellal, A. (2012). Effects of a periodized small-sided game training intervention on physical performance in elite professional soccer. Journal of Strength and Conditioning Research, 26(10), 2748-2754. doi:10.1519/JSC.0b013e318242d2d1

Padulo, J., Di Giminiani, R., Dello lacono, A., Zagatto, A. M., Migliaccio, G. M., Grgantov, Z., \& Ardigo, L. P. (2016). Lower arm muscle activation during indirect-localized vibration: The influence of skill levels when applying different acceleration loads. Front Physiol, 7, 242. doi:10.3389/ fphys.2016.00242

Padulo, J., Pizzolato, F., Tosi Rodrigues, S., Migliaccio, G. M., Attene, G., Curcio, R., \& Zagatto, A. M. (2016). Task complexity reveals expertise of table tennis players. The Journal of Sports Medicine and Physical Fitness, 56(1-2), 149-156.

Picabea, J. M., Cámara, J., \& Yanci, J. (2017). Physical fitness analysis in male and female table tennis players and their relationship to competition performance. Revista Internacional de Ciencias del Deporte, 47, 39-51.

Pradas de la Fuente, F., González Jurado, J. A., Molina Sotomayor, E., \& Castellar Otín, C. (2013). Anthropometric characteristics, body composition and somatotype of high level table tennis players. International Journal of Morphology, 31(4), 1355-1364. doi:10.4067/S071795022013000400033

Ranchordas, M. K., Rogersion, D., Ruddock, A., Killer, S. C., \& Winter, E. M. (2013). Nutrition for tennis: Practical recommendations. Journal of Sports Science and Medicine, 12(2), 211-224.

Seliger, V., Ejem, M., Pauer, M., \& Safarik, V. (1973). Energy metabolism in tennis. Internationale Zeitschrift für Angewandte Physiologie, Einschliesslich Arbeitsphysiologie, 31(4), 333-340.

Sepúlveda, R. Y., Barraza, F., Soto, G. R., Báez, E., \& Tuesta, M. (2015). Anthropometric chilean table tennis players of competitive features. Nutricion Hospitalaria, 32(4), 1689-1694. doi:10.3305/nh.2015.32.4.9547

Smekal, G., von Duvillard, S. P., Rihacek, C., Pokan, R., Hofmann, P., Baron, R., ... Bachl, N. (2001). A physiological profile of tennis match play. Medicine and Science in Sports and Exercise, 33(6), 999-1005.

Sperlich, B., Koehler, K., Holmberg, H. C., Zinner, C., \& Mester, J. (2011) Table tennis: Cardiorespiratory and metabolic analysis of match and exercise in elite junior national players. International Journal of Sports Physiology and Performance, 6(2), 234-242.

Stoggl, T., \& Sperlich, B. (2014). Polarized training has greater impact on key endurance variables than threshold, high intensity, or high volume training. Frontiers in Physiology, 5, 33. doi:10.3389/fphys.2014.00033

Takeuchi, T., Kobayashi, Y., Hiruta, S., \& Yuza, N. (2001). The effect of the $40 \mathrm{~mm}$ diameter ball on table tennis rallies by elite players. International Journal of Table Tennis Sciences, 4(5), 265-277.

Tang, H., Mizoguchi, M., \& Toyoshima, S. (2002). Speed and spin characteristics of the $40 \mathrm{~mm}$ table tennis ball. International Journal of Table Tennis Sciences, 5, 278-284.

Therminarias, A., Dansou, P., Chirpaz, M. F., Eterradossi, J., \& Favre-Juvin, A. (1995). Cramps, heat stroke and abnormal biological responseds during a strenuous tennis match. In T. Reilly, M. Hughes, \& A. Lees (Eds.), Science and racket sports. London: E \& FN Spon.

Tomlin, D. L., \& Wenger, H. A. (2001). The relationship between aerobic fitness and recovery from high intensity intermittent exercise. Sports Medicine, 31(1), 1-11.

Wang, Z. M., Pierson, R. N., Jr, \& Heymsfield, S. B. (1992). The five-level model: A new approach to organizing body-composition research. American Journal of Clinical Nutrition, 56(1), 19-28.

Wenger, H. A., \& Bell, G. J. (1986). The interactions of intensity, frequency and duration of exercise training in altering cardiorespiratory fitness. Sports Medicine, 3(5), 346-356

Yuza, N., Sasaoka, K., Nishioka, N., Matsui, Y., Yamanaka, N., Ogimura, I., ... Miyashita, M. (1992). Game analysis of table tennis in top Japanese 
players of different playing styles. International Journal of Table Tennis Sciences, 1, 79-89.

Zagatto, A., Miranda, M. F., \& Gobatto, C. A. (2011). Critical power concept adapted for the specific table tennis test: Comparisons between exhaustion criteria, mathematical modeling, and correlation with gas exchange parameters. International Journal of Sports Medicine, 32(7), 503-510. doi:10.1055/s-0030-1270470

Zagatto, A., Papoti, M., Leite, J. V. M., \& Beneke, R. (2016). Energetics of table tennis and table tennis specific exercise testing. International Journal of Sports Physiology and Performance, 11(8), 1012-1017. doi:10.1123/ijspp.2015-0746

Zagatto, A. M., Bertuzzi, R., Miyagi, W. E., Padulo, J., \& Papoti, M. (2016). MAOD determined in a single supramaximal test: A study on the reliability and effects of supramaximal intensities. International Journal of Sports Medicine, 37(09), 700-707. doi:10.1055/s-0042-104413

Zagatto, A. M., \& Gobatto, C. A. (2012). Relationship between anaerobic parameters provided from MAOD and critical power model in specific table tennis test. International Journal of Sports Medicine, 33(8), 613620. doi:10.1055/s-0032-1304648

Zagatto, A. M., Milioni, F., Freitas, I. F., Arcangelo, S. A., \& Padulo, J. (2016). Body composition of table tennis players: Comparison between performance level and gender. Sport Sciences for Health, 12(1), 49-54. doi:10.1007/s11332-015-0252-y

Zagatto, A. M., Morel, E. A., \& Gobatto, C. A. (2010). Physiological responses and characteristics of table tennis matches determined in official tournaments. Journal of Strength and Conditioning Research, 24(4), 942-949. doi:10.1519/JSC.0b013e3181cb7003

Zagatto, A. M., Papoti, M., Caputo, F., Mendes, O. C., Denadai, B. S., Baldissera, V., \& Gobatto, C. A. (2004). Comparison between the use of saliva and blood for the minimum lactate determination in arm ergometer and cycle ergometer in table tennis players. Revista Brasileira de Medicina do Esporte, 10(6), 481-486. doi:10.1590/S151786922004000600004

Zagatto, A. M., Papoti, M., dos Reis, I. G. M., Beck, W. R., \& Gobatto, C. A. (2014). Analysis of cardiopulmonary and metabolic variables measured during laboratory and sport-specific incremental tests for table tennis performance prediction. Science and Sports, 29(2), 62-70. doi:10.1016/j. scispo.2013.08.001

Zinner, C., Sperlich, B., Wahl, P., \& Mester, J. (2015). Classification of selected cardiopulmonary variables of elite athletes of different age, gender, and disciplines during incremental exercise testing. Springerplus, 4, 544. doi:10.1186/s40064-015-1341-8 